\title{
Article
}

\section{Prevalence of coronary artery disease risk factors in firefighters in the city of Cape Town fire and rescue service - A descriptive study}

\author{
Jaron Ras, Lloyd Leach \\ Department of Sport, Recreation and Exercise Science, Faculty of Community and Health Sciences, University of \\ The Western Cape, Cape Town, South Africa
}

\begin{abstract}
Background: Over $45 \%$ of firefighter deaths are attributable to sudden cardiac death related to coronary artery disease (CAD), with many of these deaths attributed to comorbidities. The purpose of the study is to determine the prevalence of coronary artery disease (CAD) risk factors in firefighters in the City of Cape Town (CoCT).

Design and Methods: The study used a quantitative, cross-sectional and descriptive design. A total of 124 full-time firefighters were conveniently recruited between September and November 2019 from the City of Cape Town Fire and Rescue Service.

Results: The most prevalent CAD risk factors among firefighters were hypertension $(33.1 \%)$, obesity $(37.1 \%)$, cigarette smoking (39.5\%) and dyslipidaemia (40.3\%). A total of $41.9 \%$ of firefighters were categorized as low-risk, $54.8 \%$ as moderate-risk, and $3.2 \%$ as high-risk for CAD.

Conclusion: The majority of firefighters had at least one CAD risk factor, with older males having the highest prevalence of multiple CAD risk factors. Compared to other regions of the world, the $(\mathrm{CoCT})$ firefighters have higher prevalence of dyslipidaemia and cigarette smoking. Preventative behavioural strategies and education on CAD should be promoted to mitigate the development of CAD.
\end{abstract}

\section{Introduction}

Over $45 \%$ of firefighter deaths are due to sudden cardiac death, with many of these deaths attributed to comorbidities. ${ }^{1}$ Firefighting is a hazardous occupation that involves firefighters in life-threatening situations, where they are exposed to severe temperatures, tremendous cardiovascular workloads and hazardous chemicals and fumes. ${ }^{1,2}$ These severe conditions necessitate that firefighters wear protective clothing and rescue equipment that is heavy and insulated, which puts tremendous strain on the cardiovascular system. ${ }^{2,3}$ The majority of firefighters $(67 \%-85 \%)$ have at least one coronary artery disease (CAD) risk factor. ${ }^{1,4-6}$ Many firefighters have multiple CAD risk factors, thus, increasing the risk of premature morbidity and/or mortality, while on duty. $1,6,7$
Previous studies found that an alarming number of firefighters were hypertensive $(27 \%)$, dyslipidemic $(33.3 \%)$, cigarette smokers $(38 \%)$, physically inactive $(49 \%)$ and obese $(63 \%), 3,6,8-10$ Viewed collectively, the hazardous conditions of firefighting, together with the excess weight of the firefighting equipment and the multiple CAD risk factors present in many firefighters, increase the likelihood of a sudden cardiac event. ${ }^{1,5,6}$ Appropriate and timely screening of CAD risk factors will highlight the firefighters at risk, and provide data to aid in reducing firefighter casualties and the associated loss of life and property. ${ }^{1,6}$

\section{Design and Methods}

This study used a quantitative, cross-sectional and descriptive design. A total of 124 full-time firefighters, males and females, were conveniently recruited from the City of Cape Town Fire and Rescue Service. The demographic characteristics included were age, gender, marital status, family history of CAD, smoking and ethnicity using a researcher-generated questionnaire. The International Physical Activity Questionnaire (IPAQ) was used to measure physical activity. Ethnicity was self-reported by each participant, based upon the historical South African classification system, i.e., Black, mixed ethnicity, White, Indian, and other. Ethnicity was included to encompass all demographic characteristics in the Cape Town metropolitan area. The study took place between September and November 2019. All subjects gave their informed consent for inclusion before they participated in the study. The study protocol was approved by the Ethics Committee of the Biomedical Research Ethics Committee (BMREC) at the University of the Western Cape (Ethics reference number: BM19/4/3). The study was also approved by the Chief Fire Officer of the City of Cape Town Fire and Rescue Service, as well as the Director of Policy and Strategy of the City of Cape Town. All the information obtained from the participants remained confidential. No personal information of the participants will be disclosed to the Fire Department that could compromise the confidentiality of the participants. All information regarding this research is stored securely in the SRES department, with access available to the researcher and supervisor only.

Significance for public health

This paper adds new knowledge on coronary artery disease (CAD) risk factors in firefighters, in the City of Cape Town Fire and Rescue Service. This study also provides valuable research into a scarcely studied research field. This article highlights the high prevalence of CAD risk factors present in firefighters and the general community of Cape Town, and the need for immediate corrective measures including behavioural modification to reduce these risk factors, and education on preventative measures. There is a high prevalence of CAD risk factors among firefighters, both male and female, in the Fire and Rescue Service in the City of Cape Town that likely contributes to premature morbidly and mortality in this population. 


\section{Research measures}

Stature was measured using a portable stadiometer, standing barefoot on the level plastic plate with the heels together, and the heels, buttocks and upper back aligned to the stadiometer rod in the Frankfort plane. Body mass was measured with the participant wearing minimal indoor clothing and measured to the nearest 50 grams using a precision electronic scale. Blood pressure was measured using a standard blood pressure sphygmomanometer and stethoscope, with the appropriate cuff size. The standard auscultatory method of blood pressure measurement was used. ${ }^{11}$ Total cholesterol and non-fasting blood glucose were measured using the finger-prick method and analysed with an AcuTrend ${ }^{\circledR}$ Plus GC meter. Waist circumference was measured at the point of the umbilicus, ${ }^{11}$ between the lower costal border and top of the iliac crest, perpendicular to the long axis of the trunk. Hip circumference was taken at the level of the greatest posterior protuberance of the buttocks. Waist and hip circumferences were measured to the nearest $0.1 \mathrm{~cm}$ at the end of normal expiration. ${ }^{11}$ The crosshand technique was used to measure all circumferences, using a steel tape measure. ${ }^{11}$ The research instruments used for data collection were calibrated, prior to testing. A minimum test-retest reliability coefficient of 0.8 was required prior to the commencement of the study and only one tester was used in the study. ${ }^{11}$

\section{Analysis}

All data was captured by double-entry into a Microsoft Office Excel spreadsheet, and then cleaned of errors. Thereafter, it was exported to the Statistical Package for the Social Sciences version 26 for descriptive data analysis. Firefighters were then separated into gender, age and ethnic groups. Firefighters were categorized into CAD risk categories using the ACSM guidelines ninth edition. ${ }^{12}$ Mann-Whitney $\mathrm{U}$ and Kruskal-Wallis $\mathrm{H}$ was used to determine statistical differences between groups and a p-value of less than 0.05 was used to indicate statistical significance.

\section{Results}

The mean age of the firefighters was $37.53 \pm 9.05$ years, and the mean body mass and stature were 87.4 kilograms $(\mathrm{kg})$ and 172.6 centimetres $(\mathrm{cm})$, respectively. The majority of firefighters were male $(79.0 \%)$, and $20.9 \%$ were female. The mean age, body mass and stature were $37.8 \pm 9.8$ years, $87.8 \mathrm{~kg}$ and $174.7 \mathrm{~cm}$ for males, and $36.4 \pm 5.4$ years, $85.9 \mathrm{~kg}$ and $164.8 \mathrm{~cm}$ for females. When all participants were separated into age-group categories, the agegroup 20-29 years represented $19.4 \%$ of the participants in the study, the age-group 30-39 years had the highest with $44.4 \%$, the age-group 40-49 years had $24.2 \%$, and the age-group 50-65 years had the lowest with $12.1 \%$. The majority of firefighters were of mixed ethnicity (56.5\%), followed by Black firefighters $(25.8 \%)$, and then White firefighters $(16.9 \%)$.

In the study, $41.9 \%$ of firefighters were categorized as low-risk ( $\leq 1$ CAD risk factor), $54.8 \%$ were moderate-risk ( $\geq 2$ CAD risk factors), and 3.2\% were high-risk (diagnosed with known CAD or presented with signs and symptoms of CAD) (Table 1). Based on gender, firefighters categorized as low-risk were $50 \%$ and $39.8 \%$ for females and males, respectively, and firefighters at moderaterisk were $50 \%$ and $56.0 \%$ for females and males, respectively. Only male firefighters were categorized as high-risk (4.1\%). Firefighters at moderate-risk for CAD increased with age, with the age-group 20-29 years reporting 29.2\% at moderate-risk, the agegroup 30-39 years with $47.3 \%$, the age-group $40-49$ years with
$76.7 \%$, and the age-group $50-65$ years with $80.1 \%$. Only the agegroups of 20-29 and 50-65 years were at high-risk for CAD, with $8.3 \%$ and $13.3 \%$, respectively. Black firefighters reported the lowest prevalence of moderate risk for CAD with $37.5 \%$, followed by firefighters of mixed ethnicity with $60.1 \%$, and White firefighters with $66.7 \%$. Firefighters categorized as high-risk for CAD were $2.9 \%$ and $9.5 \%$, for mixed ethnic and White firefighters, respectively.

Diabetes was the CAD risk factor least prevalent $(8.9 \%)$ in firefighters (Figure 1) and was prevalent amongst male firefighters only (Table 2). Based on age-group, diabetes was absent in the youngest group 20-29 years, while the age-group 30-39 years had $1.8 \%$. The age-group 40-49 years had a diabetes prevalence of $26.7 \%$, and the age-group 50-65 years had the highest with $33.4 \%$. The prevalence of diabetes among the various ethnic groups was $6.3 \%$ in Black firefighters, $9.5 \%$ in White firefighters, and $10.0 \%$ in firefighters of mixed ethnicity.

Physical inactivity was prevalent in $13.7 \%$ of firefighters (Figure 1). Both male and female firefighters had a similar prevalence for physical inactivity, $13.3 \%$ and $15.4 \%$, respectively (Table 2 ). The youngest age-group 20-29 years had physical inactivity in $20.8 \%$, the age-group 30-39 years had 9.1\%, the age-group 40-49 years had $6.7 \%$, and the age-group 50-65 years had the highest with $33.4 \%$. According to ethnic groups, White firefighters had physical inactivity in $9.5 \%$, Black firefighters with $12.5 \%$ and firefighters of mixed ethnicity with $15.7 \%$.

A total of $20.9 \%$ of firefighters reported a positive family history of CAD (Figure 1). Males and females reported a similar prevalence of family history in $21.4 \%$ and $19.2 \%$, respectively (Table 2). According to age-group, family history was prevalent in $12.5 \%$ of firefighters aged $20-29$ years, in $10.9 \%$ of firefighters aged $30-39$ years, in $46.7 \%$ of firefighters aged $40-49$ years, and in $20.0 \%$ of firefighters aged $50-65$ years. A positive family history was present in $6.3 \%$ of Black firefighters, in $22.9 \%$ of firefighters of mixed ethnicity, and in $38.1 \%$ of White firefighters.

A total of $23.4 \%$ of firefighters had age as a CAD risk factor (Figure 1), and they were all male (29.6\%) (Table 2). Age, as a CAD risk factor, was absent in the age groups 20-29 years and 3039 years, while the age-group $40-49$ years had $56.7 \%$ with age as

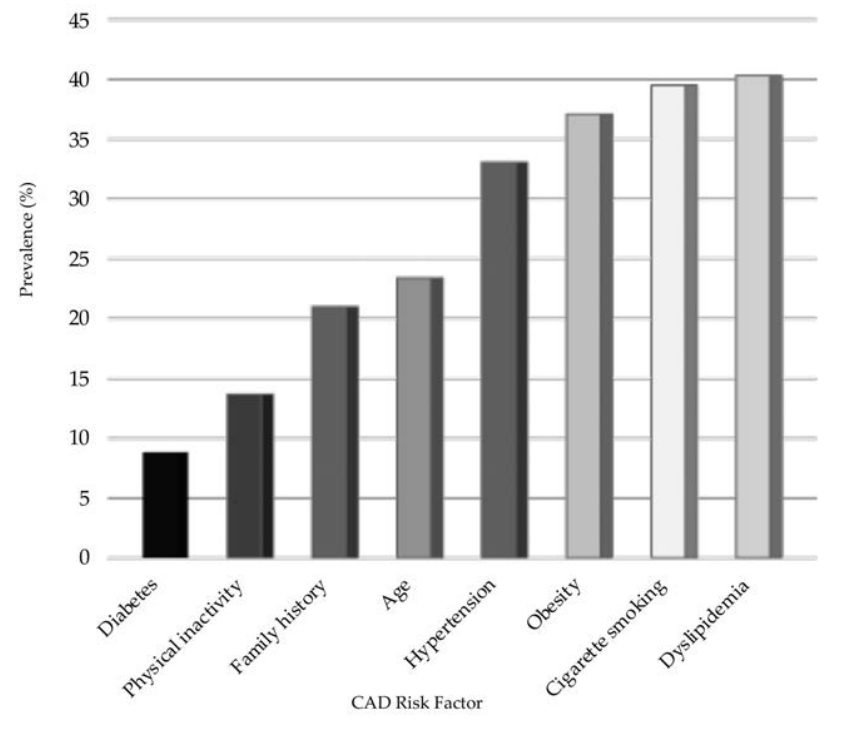

Figure 1. Prevalence of CAD risk factors in firefighters. 
a risk factor, and the age-group 50-65 years had all firefighters with age as a risk factor. Age was a risk factor in $9.4 \%$ of Black firefighters, in $19.0 \%$ of White firefighters and in $25.7 \%$ of firefighters of mixed ethnicity.

A total of $33.1 \%$ of firefighters had hypertension as a CAD risk factor (Figure 1). Among male firefighters, 34.7\% had hypertension, and among female firefighters, $26.9 \%$ had hypertension
(Table 2). In the age-group 20-29 years, 8.3\% had hypertension, the age-group 30-39 years had $29.1 \%$, the age-group 40-49 years had $50.0 \%$, and the age-group 50-65 years had the highest with $53.3 \%$. Black and White firefighters had a similar prevalence of hypertension in $28.1 \%$ and $28.6 \%$, respectively. Firefighters of mixed ethnicity had the highest prevalence of hypertension in $37.1 \%$. Among all firefighters, $18.6 \%$ were pre-hypertensive and

Table 1. CAD risk stratification in firefighters.

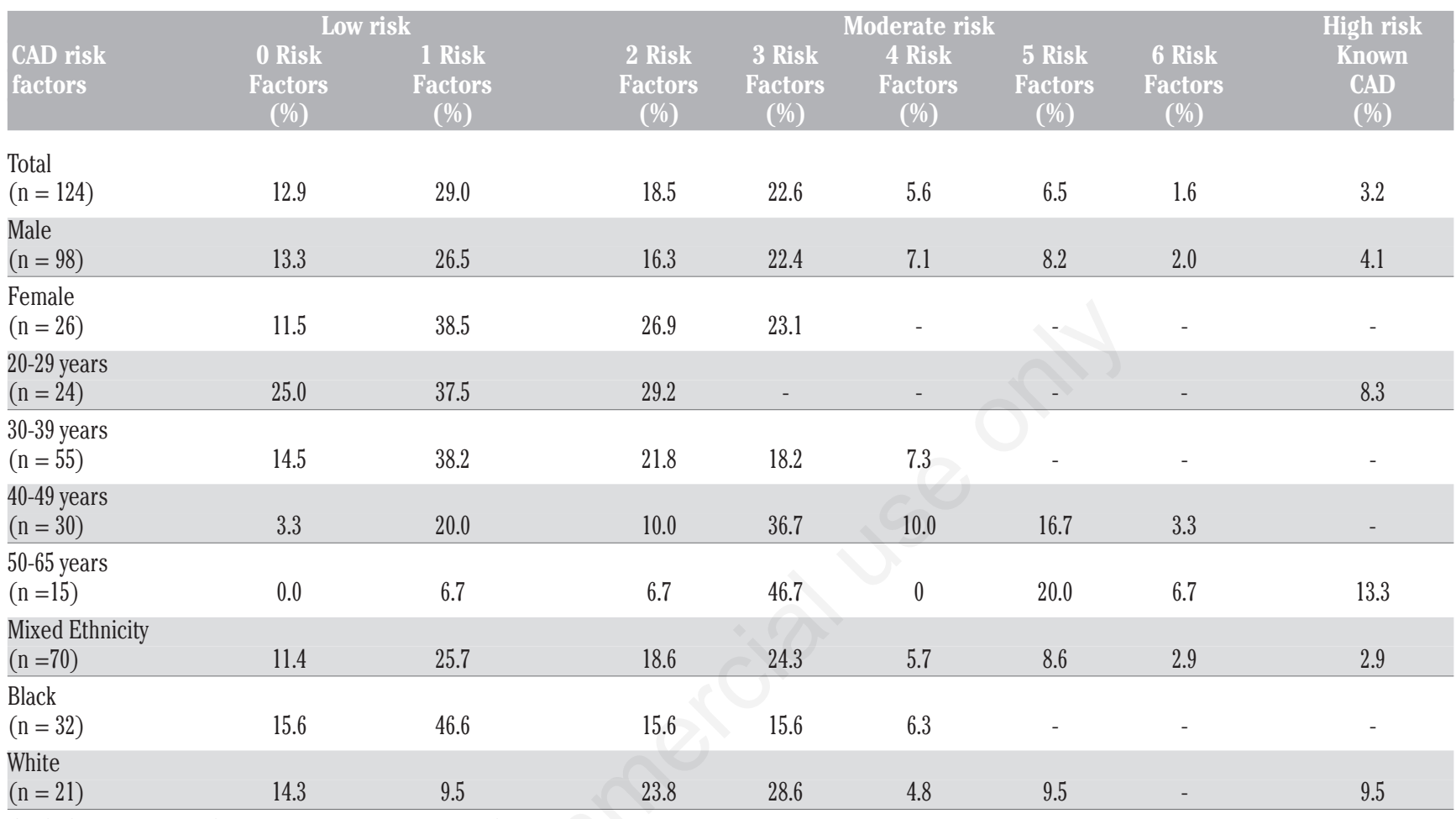

One firefighter was excluded from the ethnic groups, because he was of Indian descent.

Table 2. Prevalence of CAD risk factors among firefighters according to gender, age-group and ethnicity.

\begin{tabular}{|c|c|c|c|c|c|c|c|c|c|}
\hline \multirow[b]{2}{*}{ CAD risk factor } & \multicolumn{2}{|c|}{ Gender } & \multicolumn{4}{|c|}{ Age Group } & \multicolumn{3}{|c|}{ Ethnicity \# } \\
\hline & $\begin{array}{c}\text { Male } \\
(\mathrm{n}=98) \\
\%\end{array}$ & $\begin{array}{c}\text { Female } \\
(\mathrm{n}=26) \\
\%\end{array}$ & $\begin{array}{c}20-29 \\
(\mathrm{n}=24) \\
\%\end{array}$ & $\begin{array}{c}30-39 \\
(\mathrm{n}=55) \\
\%\end{array}$ & $\begin{array}{c}40-49 \\
(n=30) \\
\%\end{array}$ & $\begin{array}{c}50-65 \\
(n=15) \\
\%\end{array}$ & $\begin{array}{l}\text { Mixed Ethnicity } \\
\qquad(\mathrm{n}=70) \\
\%\end{array}$ & $\begin{array}{c}\text { Black } \\
(\mathrm{n}=32) \\
\%\end{array}$ & $\begin{array}{c}\text { White } \\
(n=21) \\
\%\end{array}$ \\
\hline Age (o' $\geq 45 y$; 우 $\geq 55 \mathrm{y}$ ) & 29.6 & 0.0 & 0.0 & 0.0 & 56.7 & 100 & 25.7 & 9.4 & 19.0 \\
\hline Family history ( $(-)$ (o" $\leq 55 y$; 우 $\leq 65 y)$ & ) 21.4 & 19.2 & 12.5 & 10.9 & 46.7 & 20.0 & 22.9 & 6.3 & 38.1 \\
\hline Cigarette smoking (..-) & 44.9 & 19.2 & 45.8 & 43.6 & 30.0 & 33.3 & 41.4 & 28.1 & 47.6 \\
\hline Physical inactivity ( $\mathbf{\sim}$ ) & 13.3 & 15.4 & 20.8 & 9.1 & 6.7 & 33.3 & 15.7 & 12.5 & 9.5 \\
\hline $\begin{array}{l}\text { Obesity }\left(\mathrm{BMI} \geq 30{\mathrm{~kg} \bullet \mathrm{m}^{-2}}^{2}\right. \\
\text { OverweightPC (I) } \\
\text { WC (II) } \\
\text { WHR (III) }\end{array}$ & $\begin{array}{l}31.6 \\
45.9 \\
29.6 \\
33.7\end{array}$ & $\begin{array}{l}53.9 \\
30.8 \\
65.0 \\
42.3\end{array}$ & $\begin{array}{l}12.5 \\
41.7 \\
20.8 \\
12.5\end{array}$ & $\begin{array}{l}32.7 \\
43.6 \\
34.5 \\
29.1\end{array}$ & $\begin{array}{l}53.3 \\
40.0 \\
53.3 \\
46.7\end{array}$ & $\begin{array}{l}53.3 \\
46.7 \\
53.3 \\
73.3\end{array}$ & $\begin{array}{l}37.1 \\
41.4 \\
38.6 \\
37.1\end{array}$ & $\begin{array}{c}31.3 \\
43.8 \\
6.3 \\
28.1\end{array}$ & $\begin{array}{l}42.9 \\
47.6 \\
42.9 \\
42.9\end{array}$ \\
\hline $\begin{array}{l}\text { Hypertension }(\geq 140 / 90 \mathrm{~mm} \mathrm{Hg}) \\
\text { Systolic }(\geq 140 \mathrm{~mm} \mathrm{Hg}) \\
\text { Diastolic }(\geq 90 \mathrm{~mm} \mathrm{Hg}) \\
\text { Pre-hypertension } \\
\text { PC }\end{array}$ & $\begin{array}{l}34.7 \\
18.4 \\
17.3 \\
18.4\end{array}$ & $\begin{array}{c}26.9 \\
7.7 \\
15.4 \\
19.2 \\
\end{array}$ & $\begin{array}{l}8.3 \\
8.3 \\
0.0 \\
8.3\end{array}$ & $\begin{array}{l}29.1 \\
10.9 \\
18.2 \\
21.8\end{array}$ & $\begin{array}{l}50.0 \\
30.0 \\
33.3 \\
20.0\end{array}$ & $\begin{array}{c}53.3 \\
20.0 \\
6.7 \\
20.0\end{array}$ & $\begin{array}{l}37.1 \\
14.3 \\
22.9 \\
17.1 \\
\end{array}$ & $\begin{array}{c}28.1 \\
21.9 \\
9.4 \\
21.9\end{array}$ & $\begin{array}{c}28.6 \\
14.3 \\
9.5 \\
19.1 \\
\end{array}$ \\
\hline $\begin{array}{l}\text { Diabetes (V) } \\
\quad \text { Pre-diabetes }^{\mathrm{PC}}(\mathrm{VI})\end{array}$ & $\begin{array}{l}11.2 \\
6.1\end{array}$ & $\begin{array}{c}0.00 \\
3.9\end{array}$ & $\begin{array}{l}0.0 \\
8.3\end{array}$ & $\begin{array}{l}1.8 \\
0.0\end{array}$ & $\begin{array}{l}26.7 \\
13.3\end{array}$ & $\begin{array}{l}33.3 \\
13.3\end{array}$ & $\begin{array}{l}10.0 \\
7.1\end{array}$ & $\begin{array}{l}6.3 \\
3.1\end{array}$ & $\begin{array}{l}9.5 \\
4.8\end{array}$ \\
\hline Dyslipidaemia (VII) & 41.8 & 34.6 & 12.5 & 40.0 & 56.7 & 53.3 & 44.3 & 31.3 & 42.9 \\
\hline
\end{tabular}

Italics indicates supporting measurements; ${ }^{\mathrm{PC}}$ pre-clinical measurement; $\delta$, male; 우, female; $\mathcal{-}$, family history myocardial infarction, coronary revascularization or sudden death; BMI , body mass index; WC, waist circumference; WHR, waist-to-hip ratio; $\ldots$ - current smoker or quit within the last 6 months; $\boldsymbol{\sim}$, not meeting the minimum ACSM exercise requirements of moderate-intensity exercise for 30 min, thrice

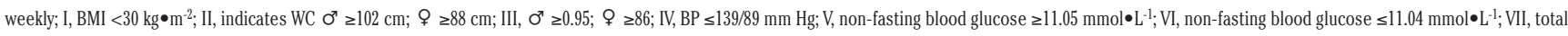
cholesterol $\geq 5.18 \mathrm{mmol} \bullet \mathrm{L}^{-1}$. One firefighter was excluded from the ethnic groups, because he was of Indian descent. 
48.4\% were normotensive (Table 2).

A total of $37.10 \%$ of firefighters were obese (Figure 1). Male firefighters had obesity in $31.6 \%$ and female firefighters had obesity in $53.9 \%$ (Table 2). The age-group 20-29 years had obesity in $12.5 \%$, followed by the age-group $30-39$ years with $32.7 \%$. The older two age-groups, 40-49 years and 50-65 years, had the same obesity prevalence of $53.3 \%$ each. Obesity was prevalent in $31.3 \%$ of Black firefighters, in $37.1 \%$ of firefighters of mixed ethnicity and in $42.9 \%$ of White firefighters. Furthermore, central obesity was prevalent in $29.6 \%$ of male firefighters and in $65.0 \%$ of female firefighters (Table 2). Central obesity was least prevalent in the youngest age-group 20-29 years with $20.8 \%$, followed by the group 30-39 years with $34.5 \%$, and the two older age-groups i.e., 40-49 years and 50-65 years, with $53.3 \%$ each. Central obesity was prevalent in $28.1 \%$ of Black firefighters, in $38.6 \%$ of firefighters of mixed ethnicity and in $42.9 \%$ of White firefighters.

A total of $39.5 \%$ of firefighters were categorized as current cigarette smokers (Figure 1). Among the male firefighters, $44.9 \%$ were smokers, compared to $19.2 \%$ of female firefighters who smoked (Table 2). Among the smokers, 36.7\% smoked less than 5 cigarettes per day and were classified as light smokers, $51.0 \%$ smoked 6 to 19 cigarettes a day and were classified as moderate smokers, and $14.3 \%$ smoked 20 or more cigarettes a day and were classified as heavy smokers. The youngest age-group of 20-29 years had the highest prevalence of smokers (45.8\%), followed by the age-group 30-39 years with $43.6 \%$. The age-group $40-49$ years had the lowest prevalence of smokers with $30.0 \%$, and the group 50-65 years had 33.3\%. Cigarette smoking was prevalent in $28.1 \%$ of Black firefighters, in $41.4 \%$ of firefighters of mixed ethnicity and in $47.6 \%$ of White firefighters.

Dyslipidaemia was the most prevalent CAD risk factor amongst the firefighters and was present in $40.3 \%$ of firefighters (Figure 1). Dyslipidaemia among male and female firefighters was prevalent in $41.8 \%$ and $34.6 \%$, respectively (Table 2). Dyslipidaemia was least prevalent in the youngest age-group 2029 years with $12.5 \%$ and increased rapidly in the group 30-39 years to $40.0 \%$, and increased even further in the group $40-49$ years to $56.7 \%$, and in the $50-65$ years it stabilized at $53.3 \%$. Dyslipidaemia was prevalent in $31.3 \%$ of Black firefighters, in
$42.9 \%$ of White firefighters and in $44.3 \%$ of firefighters of mixed ethnicity.

The mean BMI for all firefighters was $29.31 \pm 5.65 \mathrm{~kg}^{\cdot} \mathrm{m}^{-2}$ (Table 3), and for male firefighters $28.66 \pm 5.30 \mathrm{~kg}^{\cdot} \mathrm{m}^{-2}$, and for female firefighters $31.72 \pm 6.34 \mathrm{~kg}^{\cdot} \mathrm{m}^{-2}$. There was a significant difference in BMI between male and female firefighters $[\mathrm{U}=889.00$, $\mathrm{p}=0.018]$. The mean BMIs for the age groups 20-29 years, 30-39 years, 40-49 years, and 50-65 years were $25.65 \pm 3.56,28.99 \pm 5.38$, $31.38 \pm 5.38$, and $32.18 \pm 6.36 \mathrm{~kg}^{\circ} \mathrm{m}^{-2}$, respectively. There was a significant difference in BMI between age groups $[\mathrm{H}(3)=20.41$, $\mathrm{p}<0.001]$. The mean BMIs for White, mixed ethnicity and Black firefighters $30.79 \pm 5.88,29.11 \pm 5.75,28.94 \pm 5.44$ and $\mathrm{kg}^{\cdot} \mathrm{m}^{-2}$, respectively. There was no significant difference in BMI based on ethnicity $[\mathrm{H}(2)=1.87, \mathrm{p}=0.392]$.

The mean WC for all firefighters was $96.41 \pm 14.2 \mathrm{~cm}$ (Table 3), and for male firefighters $96.09 \pm 14.21 \mathrm{~cm}$, and for female firefighters $97.59 \pm 14.37 \mathrm{~cm}$. There was no significant difference in WC between male and female firefighters $[\mathrm{U}=1229.50, \mathrm{p}=0.785]$. The mean WC of firefighters increased with age, with the age-group 20-29 years having $86.32 \pm 9.80 \mathrm{~cm}$, the $30-39$ years with $94.62 \pm 13.10 \mathrm{~cm}$, the $40-49$ years with $102.49 \pm 13.17 \mathrm{~cm}$, and the $50-65$ years with $106.90 \pm 14.39 \mathrm{~cm}$. There was a significant difference in WC by age group $[\mathrm{H}(3)=28.55, \mathrm{p}<0.001]$. The mean WCs for White, mixed ethnicity and Black firefighters were $100.63 \pm 13.48,97.14 \pm 14.25$, and $92.36 \pm 14.04 \mathrm{~cm}$, respectively. There was no significant difference in WC based on ethnicity $[\mathrm{H}(2)=5.92, \mathrm{p}=0.052]$.

The mean WHR for all firefighters was $0.90 \pm 0.09$, and for male and female firefighters, $0.91 \pm 0.08$ and $0.85 \pm 0.66$, respectively. There was a significant difference in WHR between male and female firefighters $[\mathrm{U}=679.00, \mathrm{p}<0.001]$. The mean WHRs were age-related, and for age groups 20-29 years, 30-39 years, 40-49 years and $50-65$ years they were $0.85 \pm 0.06,0.88 \pm 0.65,0.93 \pm 0.11$ and $0.97 \pm 0.05$, respectively. There was a significant difference in WHR between age groups $[\mathrm{H}(3)=30.41, \mathrm{p}<0.001]$. The mean WHR for mixed ethnicity, White and Black firefighters were $0.92 \pm 0.09,0.92 \pm 0.07$ and $0.85 \pm 0.07$, respectively. There was a significant difference in WHR between ethnic groups $[\mathrm{H}(2)=$ 15.99, $\mathrm{p}<0.001]$.

Table 3. CAD risk factor measurements according to demographic characteristics.

\begin{tabular}{|c|c|c|c|c|c|c|c|c|c|c|c|c|c|c|}
\hline \multirow[b]{2}{*}{$\begin{array}{l}\text { CAD risk } \\
\text { factor }\end{array}$} & \multirow[b]{2}{*}{$\begin{array}{c}\bar{X} \\
\text { SD }\end{array}$} & \multirow[b]{2}{*}{$\begin{array}{c}\text { Total } \\
(\mathrm{n}=124)\end{array}$} & \multicolumn{2}{|c|}{ Gender } & \multirow[b]{2}{*}{$p$} & \multicolumn{4}{|c|}{ Age Group } & \multirow[b]{2}{*}{$\mathrm{p}$} & \multicolumn{4}{|c|}{ Ethnicity\# } \\
\hline & & & $\begin{array}{c}\text { Male } \\
(\mathrm{n}=98)\end{array}$ & $\begin{array}{l}\text { Female } \\
(\mathrm{n}=24)\end{array}$ & & $\begin{array}{c}20-29 \\
(\mathrm{n}=24)\end{array}$ & $\begin{array}{c}30-39 \\
(\mathrm{n}=55)\end{array}$ & $\begin{array}{c}40-49 \\
(n=30)\end{array}$ & $\begin{array}{c}50-65 \\
(\mathrm{n}=15)\end{array}$ & & $\begin{array}{l}\text { Mixed } \\
\text { Ethnicity } \\
(n=70)\end{array}$ & $\begin{array}{c}\text { Black } \\
(\mathrm{n}=32)\end{array}$ & $\begin{array}{l}\text { White } \\
(\mathrm{n}=21\end{array}$ & p \\
\hline $\begin{array}{l}\text { Body mass index } \\
\left(\mathrm{kg} \bullet \mathrm{m}^{-2}\right)\end{array}$ & $\begin{array}{c}\bar{x} \\
S D\end{array}$ & $\begin{array}{r}29.31 \\
5.65\end{array}$ & $\begin{array}{c}28.66 \\
5.30\end{array}$ & $\begin{array}{l}31.72 \\
6.34\end{array}$ & $0.018^{*}$ & $\begin{array}{l}25.65 \\
3.56\end{array}$ & $\begin{array}{c}28.99 \\
5.53\end{array}$ & $\begin{array}{l}31.38 \\
5.38\end{array}$ & $\begin{array}{l}32.18 \\
6.36\end{array}$ & $<0.001^{* *}$ & $\begin{array}{l}29.11 \\
5.75\end{array}$ & $\begin{array}{c}28.94 \\
5.33\end{array}$ & $\begin{array}{l}30.79 \\
5.88\end{array}$ & 0.392 \\
\hline Waist circumference (cm) & $\begin{array}{c}\bar{x} \\
S D\end{array}$ & $\begin{array}{l}96.41 \\
14.19\end{array}$ & $\begin{array}{l}96.09 \\
14.21\end{array}$ & $\begin{array}{l}97.59 \\
14.37\end{array}$ & 0.785 & $\begin{array}{c}86.32 \\
9.80\end{array}$ & $\begin{array}{l}94.62 \\
13.10\end{array}$ & $\begin{array}{l}102.49 \\
13.17\end{array}$ & $\begin{array}{l}106.90 \\
14.39\end{array}$ & $<0.001^{* *}$ & $\begin{array}{l}97.14 \\
14.25\end{array}$ & $\begin{array}{l}92.36 \\
14.04\end{array}$ & $\begin{array}{l}100.63 \\
13.48\end{array}$ & 0.052 \\
\hline Waist-to-hip ratio & $\begin{array}{c}\bar{X} \\
S D\end{array}$ & $\begin{array}{l}0.90 \\
0.09\end{array}$ & $\begin{array}{l}0.91 \\
0.08\end{array}$ & $\begin{array}{l}0.85 \\
0.66\end{array}$ & $<0.001 * *$ & $\begin{array}{l}0.85 \\
0.06\end{array}$ & $\begin{array}{l}0.88 \\
0.65\end{array}$ & $\begin{array}{l}0.93 \\
0.11\end{array}$ & $\begin{array}{l}0.97 \\
0.05\end{array}$ & $<0.001^{* *}$ & $\begin{array}{l}0.92 \\
0.09\end{array}$ & $\begin{array}{l}0.85 \\
0.07\end{array}$ & $\begin{array}{l}0.92 \\
0.07\end{array}$ & $<0.001^{* *}$ \\
\hline Systolic blood pressure (mm Hg) & $\begin{array}{c}\bar{x} \\
\text { SD }\end{array}$ & $\begin{array}{r}121.69 \\
15.15 \\
\end{array}$ & $\begin{array}{l}123.06 \\
15.28\end{array}$ & $\begin{array}{l}116.54 \\
13.70\end{array}$ & 0.069 & $\begin{array}{r}117.50 \\
11.62\end{array}$ & $\begin{array}{l}119.16 \\
13.73\end{array}$ & $\begin{array}{c}127.93 \\
16.73 \\
\end{array}$ & $\begin{array}{l}125.20 \\
18.34\end{array}$ & $0.050^{*}$ & $\begin{array}{l}121.63 \\
14.89\end{array}$ & $\begin{array}{c}121.19 \\
16.99 \\
\end{array}$ & $\begin{array}{c}123.24 \\
13.78 \\
\end{array}$ & 0.774 \\
\hline Diastolic blood pressure (mm Hg) & $\begin{array}{c}\bar{X} \\
S D\end{array}$ & $\begin{array}{l}77.10 \\
11.69\end{array}$ & $\begin{array}{l}78.10 \\
11.46\end{array}$ & $\begin{array}{l}73.31 \\
11.95\end{array}$ & 0.125 & $\begin{array}{l}71.92 \\
10.26\end{array}$ & $\begin{array}{l}75.75 \\
11.47\end{array}$ & $\begin{array}{l}83.33 \\
12.04\end{array}$ & $\begin{array}{c}77.87 \\
8.99\end{array}$ & $0.006 * *$ & $\begin{array}{l}78.89 \\
11.86\end{array}$ & $\begin{array}{l}72.81 \\
12.36\end{array}$ & $\begin{array}{l}77.62 \\
8.73\end{array}$ & 0.162 \\
\hline $\begin{array}{l}\text { Non-fasting blood glucose } \\
\left(\mathrm{mmol} \cdot \bullet^{-1}\right)\end{array}$ & $\begin{array}{l}\bar{x} \\
S D\end{array}$ & $\begin{array}{l}5.93 \\
2.24\end{array}$ & $\begin{array}{l}6.01 \\
2.48\end{array}$ & $\begin{array}{l}5.65 \\
0.95\end{array}$ & 0.961 & $\begin{array}{l}5.81 \\
0.93\end{array}$ & $\begin{array}{l}5.34 \\
0.87\end{array}$ & $\begin{array}{l}6.87 \\
3.91\end{array}$ & $\begin{array}{l}10.63 \\
2.16\end{array}$ & 0.135 & $\begin{array}{l}5.78 \\
1.41\end{array}$ & $\begin{array}{l}5.88 \\
2.13\end{array}$ & $\begin{array}{l}6.47 \\
4.08\end{array}$ & 0.871 \\
\hline $\begin{array}{l}\text { Total cholesterol } \\
\left(\mathrm{mmol} \bullet \mathrm{L}^{-1}\right)\end{array}$ & $\begin{array}{l}\bar{x} \\
S D\end{array}$ & $\begin{array}{l}4.92 \\
0.96\end{array}$ & $\begin{array}{l}4.93 \\
0.99\end{array}$ & $\begin{array}{l}4.84 \\
0.79\end{array}$ & 0.909 & $\begin{array}{l}4.46 \\
0.92\end{array}$ & $\begin{array}{l}5.03 \\
0.92\end{array}$ & $\begin{array}{l}5.13 \\
0.96\end{array}$ & $\begin{array}{l}4.79 \\
1.12\end{array}$ & $0.006 * *$ & $\begin{array}{l}5.02 \\
0.94\end{array}$ & $\begin{array}{l}4.68 \\
0.87\end{array}$ & $\begin{array}{l}4.96 \\
1.13\end{array}$ & 0.199 \\
\hline
\end{tabular}

Ethnicity\#: $\mathrm{n}=123$ due to one firefighter not falling into the three-ethnic group; ${ }^{*}$ statistically significant differences $<0.05 ;{ }^{* *}$ statistically significant differences $<0.01$. 
The mean SBP for all firefighters was $121.69 \pm 15.15 \mathrm{~mm} \mathrm{Hg}$, and the mean DBP was $77.10 \pm 11.69 \mathrm{~mm} \mathrm{Hg}$ (Table 3). The mean SBPs for male and female firefighters were $123.06 \pm 15.29 \mathrm{~mm} \mathrm{Hg}$ and $116.54 \pm 13.70 \mathrm{~mm} \mathrm{Hg}$, respectively, and the mean DBPs for male and female firefighters were $78.10 \pm 11.46 \mathrm{~mm} \mathrm{Hg}$ and $73.31 \pm 11.95 \mathrm{~mm} \mathrm{Hg}$, respectively. There was no significant difference in SBP [U = 978.00, $\mathrm{p}=0.069]$ or DBP [ $\mathrm{U}=97.00, \mathrm{p}=0.056]$. The mean SBP and DBP for the age-group 20-29 years were $117.50 \pm 11.62$ and $71.92 \pm 10.26 \mathrm{~mm} \mathrm{Hg}$, respectively. In the agegroup 30-39 years the mean SBP and DBP were 119.16 \pm 13.73 and $75.75 \pm 11.47 \mathrm{~mm} \mathrm{Hg}$, respectively. In the age-group 40-49 years the mean SBP and DBP were $127.93 \pm 16.73$ and $83.33 \pm 12.04 \mathrm{~mm}$ $\mathrm{Hg}$, respectively. And, in the age-group 50-65 years the mean SBP and DBP were $125.20 \pm 18.34$ and $77.87 \pm 8.99 \mathrm{mmHg}$, respectively. There was a significant difference in both SBP $[\mathrm{H}(3)=7.82$, $\mathrm{p}=0.050]$ and $\mathrm{DBP}[\mathrm{H}(3)=12.44, \mathrm{p}=0.006]$ based on age-group. The mean SBP and DBP for White firefighters were 123.24 \pm 13.78 and $77.62 \pm 8.73 \mathrm{~mm} \mathrm{Hg}$, mixed ethnicity firefighters were $121.63 \pm 14.89$ and $78.89 \pm 11.86 \mathrm{~mm} \mathrm{Hg}$, and for Black firefighters were $121.19 \pm 16.99$ and $72.81 \pm 12.36 \mathrm{~mm} \mathrm{Hg}$, respectively. There was no significant difference in $\operatorname{SBP}[\mathrm{H}(2)=0.51, \mathrm{p}=0.774]$ or $\mathrm{DBP}[\mathrm{H}(2)=3.64, \mathrm{p}=0.162]$ based on ethnic groups.

The mean NFBG concentration was $5.93 \pm 2.24 \mathrm{mmol}^{\circ} \mathrm{L}^{-1}$ for all firefighters, with male firefighters having $6.01 \pm 2.48 \mathrm{mmol}^{\circ} \mathrm{L}^{-1}$, and female firefighters having $5.65 \pm 0.95 \mathrm{mmol}^{\circ} \mathrm{L}^{-1}$ (Table 3). No significant difference in NFBG was found between male and female firefighters $[\mathrm{U}=126.00, \mathrm{p}=0.961]$. The mean $\mathrm{NFBG}$ was $5.81 \pm 0.93 \mathrm{mmol}^{\circ} \mathrm{L}^{-1}$ in the age-group 20-29 years, $5.34 \pm 0.87$ $\mathrm{mmol}^{\circ} \mathrm{L}^{-1}$ in the $30-39$ years, $6.87 \pm 3.91 \mathrm{mmol}^{\circ} \mathrm{L}^{-1}$ in the $40-49$ years, and $10.63 \pm 2.16 \mathrm{mmol}^{\circ} \mathrm{L}^{-1}$ in the $50-65$ years. There was no significant difference in NFBG between age groups $[\mathrm{H}(3)=5.56$, $\mathrm{p}=0.135]$. The mean NFBG concentration was highest in White firefighters with $6.47 \pm 4.08 \mathrm{mmol}^{\circ} \mathrm{L}^{-1}$, followed by Black firefighters with $5.88 \pm 2.13 \mathrm{mmol}^{\circ} \mathrm{L}^{-1}$, and lowest in mixed ethnicity firefighters with $5.78 \pm 1.41 \mathrm{mmol}^{\circ} \mathrm{L}^{-1}$. There was no significant difference in NFBG between ethnic groups $[\mathrm{H}(2)=0.28, \mathrm{p}=0.871]$.

The mean TC was $4.92 \pm 0.96 \mathrm{mmol}^{\circ} \mathrm{L}^{-1}$ for all firefighters (Table 3), and for male and female firefighters, $4.93 \pm 0.99$ and $4.84 \pm 0.79 \mathrm{mmol}^{*} \mathrm{~L}^{-1}$, respectively. There was no significant difference in TC between male and female firefighters $[\mathrm{U}=1255.50$, $\mathrm{p}=0.909]$. The mean TC concentration was $4.46 \pm 0.92 \mathrm{mmol}^{\circ} \mathrm{L}^{-1}$ for the age-group 20-29 years, $5.03 \pm 0.92 \mathrm{mmol}^{*} \mathrm{~L}^{-1}$ for the $30-39$ years, $5.13 \pm 0.96 \mathrm{mmol}^{\circ} \mathrm{L}^{-1}$ for the $40-49$ years, and $4.79 \pm 1.12$ $\mathrm{mmol}{ }^{\circ} \mathrm{L}^{-1}$ for the $50-65$ years. There was a significant difference in TC between age groups $[\mathrm{H}(3)=12.44, \mathrm{p}=0.006]$. Mixed ethnicity firefighters had the highest mean TC with $5.02 \pm 0.94 \mathrm{mmol}^{\circ} \mathrm{L}^{-1}$, followed by white firefighters with $4.96 \pm 1.13 \mathrm{mmol}^{\circ} \mathrm{L}^{-1}$, and black firefighters with $4.68 \pm 0.87 \mathrm{mmol}^{\circ} \mathrm{L}^{-1}$. There was no significant difference in TC between ethnic groups $[\mathrm{H}(2)=3.23, \mathrm{p}=0.199]$.

\section{Discussion}

A total of $83.8 \%$ of firefighters had at least one CAD risk factor, while $54.8 \%$ had at least two risk factors, and $36.3 \%$ had three or more risk factors. Additionally, $41.9 \%$ of firefighters were categorized as being at low-risk, $54.8 \%$ were categorized as being at moderate-risk and 3.2\% were categorized as being at high-risk for CAD. Gendron et al. ${ }^{4}$ reported a similar prevalence in Québec firefighters, where $85 \%$ of firefighters had at least one risk factor and $59.1 \%$ reported two or more risk factors, placing them at moderate-risk. Similarly, Martin et al. ${ }^{6}$ reported that $32.4 \%$ of firefighters in the United States (US) reported having zero or one CAD risk factor, $67.6 \%$ had two or more risk factors, and $51.4 \%$ had at least three or more risk factors. Smith et al. ${ }^{1}$ reported $20.4 \%$ of US firefighters had zero or one risk factor, and that $45.9 \%$ of firefighters had two or more risk factors.

Among female firefighters, $38.5 \%$ reported a prevalence of one and $26.9 \%$ had two or three CAD risk factors, whereas only male firefighters had four or more risk factors. Gendron et al. ${ }^{4}$ reported that $73 \%$ of female firefighters had at least one CAD risk factor, and $22 \%$ had at least two risk factors. Similarly, Wolkow et al..$^{5}$ reported that $46.6 \%$ and $26.6 \%$ of female and male Australian firefighters, respectively, had one or less risk factors, and that $50.8 \%$ of female firefighters had two or more risk factors compared to $68.2 \%$ of male firefighters. The present study, as well as previous literature indicate male firefighters more frequently have multiple risk factors and are at higher risk compared to female firefighters. ${ }^{4,5}$

Firefighters categorized as moderate-risk increased with age, with the age-group 20-29 years reporting $29.2 \%$ with two or more risk factors, the age-group 30-39 years with $47.3 \%$, the age-group 40-49 years with $76.7 \%$, and the age-group 50-65 years with $80.0 \%$. Byczek et al. ${ }^{13}$ also reported that in the US, CAD risk generally increased as firefighters aged, with $74 \%$ of firefighters at moderate $\mathrm{CAD}$ risk in the age-group 30-34 years, $40 \%$ at moderate risk in the age-group 35-39 years, $51 \%$ in the age-group $40-44$ years, $79 \%$ in the age-group $45-49$ years, $67 \%$ in the age-group 50 59 years, and $87 \%$ in the age-group $60-64$ years. Although Black firefighters reported the lowest prevalence of two or more CAD risk factors, the prevalence was still unacceptably high at $37.5 \%$, followed by firefighters of mixed ethnicity with $60.8 \%$ and White firefighters with $66.7 \%$.

Diabetes was the least prevalent CAD risk factor in firefighters, and in males only, especially above the age of forty years, and unrelated to ethnicity. Savall et al. ${ }^{9}$ reported a similar low prevalence of diabetes in French firefighters, where 3.2\% of firefighters had diabetes. The present study reported an absence of diabetes in female firefighters, while Wolkow et al. ${ }^{14}$ reported that female firefighters had a slightly lower prevalence of diabetes compared to male firefighters (3.6\% vs 6.8, respectively). Studies by Gendron et al. ${ }^{4,15}$ reported similar low results for diabetes prevalence in both genders, but with female Québec firefighters slightly higher than male firefighters (3\% vs $1.7 \%$, respectively). With regard to ethnicity, Padela et al. ${ }^{16}$ reported a similar prevalence of diabetes in the US across ethnic groups, as did the present study. Previous studies found no significant differences between diabetes and gender or ethnicity, however, a significant association was reported between diabetes and age in firefighters. ${ }^{1,17-19}$ The prevalence of diabetes can be attributed partially to the firefighters' variable work schedules which, in most cases, demands a maximal response when dealing with an emergency. This, invariably, leads to increased stress, both physiological and psychological, and adversely impacts blood sugar levels. ${ }^{20,21}$ In addition, indulging in fast-foods tends to be the unhealthy first choice of many firefighters that aggravates their diabetes risk. ${ }^{4,9,20}$

The minority $(13.7 \%)$ of firefighters were classified as physically inactive ${ }^{11}$ in the current study, with the age-group 40-49 years the most likely to be physically inactive, for both genders and all ethnicities. Mehrdad et al. ${ }^{22}$ reported a slightly higher prevalence of physical inactivity in Tehran firefighters at $23.8 \%$. Eastlake et al. ${ }^{18}$ reported a much higher prevalence for physical inactivity in US firefighter, with $62 \%$, respectively. The present study reported a similar prevalence of physical inactivity for males and females in $13.3 \%$ and $15.4 \%$, respectively. Gendron et al. ${ }^{4,15}$ reported that $62 \%$ of female firefighters were physically inactive compared to 
$70 \%$ of male firefighters. According to ethnicity, Poston et al. ${ }^{16}$ reported a similar prevalence of physical inactivity in firefighters across various ethnic groups, similar to the present study. Although the prevalence of physical inactivity was not high in firefighters in the current study, it remains a cause of concern from both a public safety point of view, as well as from a personal health perspective. Therefore, encouraging physical activity among firefighters, who are at risk, will help to address physical inactivity as a modifiable CAD risk factor. ${ }^{2,3}$ The current study had a much lower prevalence of physical inactivity compared to previous literature and can be accounted for by the researchers using the IPAQ questionnaire as a means to categorize activity levels of the firefighters.

For family history, $20.9 \%$ of firefighters indicated a positive family history of CAD that was similar in both genders and related to advancing age in male firefighters. Martin et al. ${ }^{6}$ reported a similar prevalence of family history in $25 \%$ of firefighters. Smith et al. ${ }^{1}$ reported a much lower prevalence of family history in $5.2 \%$ of firefighters. Mehrdad et al. ${ }^{22}$ reported a similar low prevalence of family history in $6.1 \%$ of firefighters. Gendron et al. ${ }^{4,15}$ reported a similar prevalence of family history as the present study, based on gender. Santora et al. ${ }^{23}$ reported a much higher prevalence of family history in $38 \%$ of male and in $56 \%$ of female firefighters in the US. A positive family history of CAD in firefighters varied quite broadly among studies, ranging from $5 \%$ to $56 \%, 6,9,24$ and was likely due to differences in study sample size, gender, and age.

In the present study, $23.4 \%$ of firefighters had age ( 45 years or older) as a CAD risk factor, especially in White firefighters and those of mixed ethnicity, but was not significantly different between gender or ethnic groups. Martin et al. ${ }^{6}$ reported that $35.1 \%$ of firefighters had age as a risk factor. Similarly, Savall et al. ${ }^{9}$ reported $31.9 \%$ of firefighters had age as a risk factor. In contrast, Mehrdad et al..$^{22}$ reported only $11.6 \%$ of firefighters had age as a risk factor. According to gender, Gendron et al..$^{4,15}$ reported that $45.3 \%$ of male firefighters had age as a risk factor compared to only $10 \%$ of female firefighters. Soteriades et al. ${ }^{17}$ reported that aged firefighters (45 years or older) had a significantly higher prevalence of hypertension than their younger counterparts. Similarly, Eastlake et al. ${ }^{18}$ reported that age in firefighters had a significant association with high blood cholesterol, high blood glucose and high blood pressure. Smith et al. ${ }^{25}$ reported that as male and female firefighters aged, both genders had a significant increase in BMI, but only male firefighters had a significant increase in hypercholesterolemia, hypertension, and hyperglycaemia. The prevalence of aged firefighters varied considerably among studies and can be attributed to the individual sample sizes and regions where data was collected. $4,6,9,15,17,18,22,25$

Hypertension was present in $33.1 \%$ of firefighters, especially male firefighters older than 40 years, and in all ethnic groups. In previous studies, female firefighters were reported to have a lower prevalence of hypertension compared to male firefighters. ${ }^{4,14,15}$ Choi et al. ${ }^{20}$ reported that $10.9 \%$ of US firefighters were hypertensive. Nor et al. ${ }^{26}$ and Soteriades et al. ${ }^{27}$ reported a similar prevalence of hypertension in $18.1 \%$ in Korean and $18.24 \%$ in US firefighters, respectively. Choi et al. ${ }^{20}$ reported both systolic and diastolic blood pressures were significantly higher in older United States firefighters, and that the prevalence of hypertension significantly increased proportionately with age-group from 25-34 years $(1.2 \%), 35-44$ years $(6.7 \%), 45-54$ years $(17.2 \%)$ to $55-61$ years $(35.0 \%)$. Soteriades et al. ${ }^{17}$ reported that hypertension was significantly associated with increased age in firefighters. Factors related to the alarm response and emergency duties, such as 24-hour shifts, night shift, sleep cycle disruption, sleep deprivation, emotional and physical stress, and altered eating patterns caused alterations in the circadian rhythm of blood pressure in firefighters. ${ }^{20,28}$ Sleep depri- vation, in combination with mental and physical stress, were significant causes of hypertension, especially in firefighters working 24-hour shifts, night shifts, and multiple shifts a month and exacerbated with increased age. ${ }^{20,28,29}$

In the current study, $37.1 \%$ of firefighters were obese, especially with central obesity in both female and male firefighters aged 40 years or older, and in all ethnic groups. Choi et al. ${ }^{21}$ and Gendron et al. ${ }^{4}$ reported a lower prevalence of obesity in $22.8 \%$ and $23.6 \%$ of firefighters, respectively. Choi et al..$^{30}$ also reported significant correlations between BMI, WC, and age in both male and female firefighters. Eastlake et al. ${ }^{18}$ reported a prevalence of obesity in $33 \%$ of firefighters. Leary et al. ${ }^{31}$ and Smith et al. ${ }^{1}$ reported a higher prevalence of obesity in $46.8 \%$ and $51.7 \%$ of US firefighters, respectively. Choi et al. ${ }^{30}$ reported that obesity significantly increased with age-group, i.e., the age-group 25-34 years had $7.8 \%$, the age-group 35-44 years had $25.5 \%$, the age-group $45-54$ years had $33.6 \%$, and the age-group 55-64 years had 38.1\%. Clark et al. ${ }^{32}$ reported an obesity prevalence of $29.8 \%$ in firefighters, with $2.3 \%$ being morbidly obese. The study also reported that DBP and cholesterol were significantly higher in obese firefighters. ${ }^{32}$ Poston et al. ${ }^{16}$ reported that firefighters of color in the US had significantly higher body mass indexes compared to White firefighters, whereas, Choi et al. ${ }^{21,30}$ reported that a higher percentage of White firefighters were obese compared to other ethnic groups in the United States. As previously stated, firefighters tend to indulge in high caloric, fat laden, fast-foods while on active duty, augmenting the accumulation of adipose tissue. ${ }^{4,9,20}$ Muegge et al. ${ }^{33}$ found that a lack of knowledge was the most common barrier to weight management $(19 \%)$ in firefighters, as well as a lack of access to low calorie foods $(15.7 \%)$. Therefore, firefighters should be educated on weight management strategies and provided with easier access to low calorie food options, where possible.

Cigarette smoking was the second most prevalent risk factor in $39.5 \%$ of firefighters, especially in male firefighters who were White and of mixed ethnicity, and particularly in the youngest agegroup 20-29 years. In contrast, Gendron et al. ${ }^{4,15}$ reported that the prevalence of cigarette smoking was higher in female firefighters. Similarly, Jahnke et al. ${ }^{34}$ reported that in the United states more female firefighters were smokers compared to male firefighters (22.2\% vs $13.6 \%$, respectively). Yoo and Franke ${ }^{35}$ reported that tobacco use was most prevalent $(40 \%)$ in the youngest age-group of under 30 years compared to the older groups of 31-42 years (32\%) and 43-69 years (19\%). Lima et al. ${ }^{36}$ reported that $8.3 \%$ of White Brazilian firefighters were smokers, $6.8 \%$ of mixed ethnicity were smokers, and $9.3 \%$ of Black firefighters were smokers. Cigarette smoking prevalence in firefighters were higher in this study than previous studies on firefighters, which is a concern, as cigarette smoking is known to reduce peak work performance in firefighters. 4,15,34,35 Firefighters should be encouraged to reduce their daily cigarette use, until complete cessation is possible.

Dyslipidaemia was the most prevalent CAD risk factor in $40.3 \%$ of firefighters in both genders and in all ethnic groups and increased with advancing age. Savall et al. ${ }^{9}$ found that $19.5 \%$ of firefighters had elevated cholesterol levels. Similarly, Byczek et al. ${ }^{13}$ reported a prevalence of hypercholesterolemia in $24 \%$ of US firefighters, and Martin et al. ${ }^{6}$ reported that $29.7 \%$ of volunteer firefighters had dyslipidaemia. Leary et al. ${ }^{31}$ reported a higher prevalence, where $46.7 \%$ of firefighters had high triglycerides, and $31.1 \%$ had low high density lipoprotein cholesterol levels. Gendron et al. ${ }^{4,15}$ reported that male firefighters had a higher prevalence of dyslipidaemia compared to females $(17.4 \%$ vs $5 \%$, respectively). Similarly, Santora et al. ${ }^{23}$ reported that hypercholesterolemia was present in $46 \%$ of male firefighters and $11 \%$ of female firefighters. Cohen et al. ${ }^{37}$ reported a prevalence of dyslip- 
idaemia in $56.5 \%$ of firefighters and that is was significantly associated with age. Burgess et al. ${ }^{38}$ reported that $26.97 \%$ of firefighters had high low density lipoprotein cholesterol (LDL-C) levels, and in the 45-year and older age-group, increased LDL-C was significantly associated with hypertension. Glueck et al. ${ }^{24}$ reported that White and Black US firefighters had a similar prevalence of hypercholesterolemia. Poston et al. ${ }^{39}$ reported that firefighters of color had a higher prevalence of hypercholesterolemia compared to White firefighters $(32.7 \%$ vs $28.1 \%$, respectively). Fast foods, which are firefighters first choice options are also high in saturated and trans-fatty acids, and are directly related to increased TC. $4,18,40$ Environmental and wildland fire smoke has been reported to cause an increase in oxidative stress and to increase certain serum haematological parameters, specifically TC, LDL-C, lactate dehydrogenase, creatine kinase and urea nitrogen. ${ }^{40}$ These factors in combination may contribute to the high prevalence of dyslipidaemia in firefighters in the City of Cape Town. $., 18,40$

\section{Strengths and limitations}

This study provides valuable research data on firefighters according to gender, age and ethnicity in a scarcely studied area, especially in South Africa. This was the first study in South Africa to look at CAD risk factors in firefighters according to gender, age and ethnicity. The study is limited by convenient sampling and a small sample size, as prescribed by the municipal authority of the City of Cape Town, that negatively impacted the external validity. The study was also under-represented by female participants, and with only one firefighter of Indian ethnicity.

\section{Recommendations}

It is recommended that future studies use random sampling that would be sufficiently powered in order to ensure external validity. A more representative sample of female firefighters in the CoCT is recommended. In addition, a larger sample size is recommended to ensure greater statistical power and generalizability of the results.

\section{Conclusion}

Hypertension, obesity, cigarette smoking and dyslipidaemia were the most prevalent CAD risk factors among firefighters, with older males having the highest prevalence of multiple CAD risk factors, especially in firefighters who were White and of mixed ethnicity. Male firefighters were more likely to be smokers, hypertensive and diabetic. Female firefighters had a higher prevalence of obesity, especially central obesity. As firefighters aged the prevalence of the CAD risk factors increased, apart from blood glucose, similar to previous literature. Compared to other regions of the world, the City of Cape Town firefighters had a higher prevalence of dyslipidaemia and cigarette smoking, with most other CAD risk factors having similar prevalence's. The high prevalence of dyslipidaemia, cigarette smoking and obesity can be attributed to firefighters opting for high caloric fast foods due to their erratic work schedules. This study highlights the high prevalence of CAD risk factors in firefighters in the City of Cape Town and the need to promote regular CAD risk factor screening and to adopt behavioural strategies to ameliorate $\mathrm{CAD}$ risk prevalence in firefighters.
Correspondence: Jaron Ras, Department of Sport, Recreation and Exercise Science, Faculty of Community and Health Sciences, University of the Western Cape, Robert Sobukwe Road, Bellville, Cape Town, 7530, Private Bag X17, Bellville, Cape Town 7535, South Africa.

Tel. +27.072.795 5518 - Fax: +27.021.9593688.

E-mail: jaronras@gmail.com

Key words: Firefighters; CAD; risk factor; cardiovascular; dyslipidaemia; cigarette smoking; hypertension.

Acknowledgments: We thank the City of Cape Town for granting permission to conduct the study, and to Mr Ian Bell for supporting the study from the start to the end. To each District Head and Station Commander that allowed testing and to every firefighter that voluntarily participated in the study.

Contributions: JR, LL, conceptualization, methodology, software utilization, Jaron Ras; validation, formal analysis, data curation, writing, review and editing; JR, investigation, resources, writing, visualization, project administration; LL, supervision. All authors have read and agreed to the published version of the manuscript.

Conflicts of interest: The authors declare no conflict of interest.

Funding: This research received no external funding.

Ethical approval: The study protocol was approved by the Ethics Committee of the Biomedical Research Ethics Committee (BMREC) at the University of the Western Cape (Ethics reference number: BM19/4/3).

Availability of data and materials: The data used to support the findings of this study are available from the corresponding author upon request.

Received for publication: 20 October 2020.

Accepted for publication: 3 December 2020.

o Copyright: the Author(s), 2021

Licensee PAGEPress, Italy

Journal of Public Health Research 2021;10:2000

doi:10.4081/jphr.2021.2000

This work is licensed under a Creative Commons Attribution NonCommercial 4.0 License (CC BY-NC 4.0).

\section{References}

1. Smith DL, Fehling PC, Frisch A, et al. The prevalence of cardiovascular disease risk factors and obesity in firefighters. J Obes 2012;2012:908267.

2. Seyedmehdi SM, Attarchi M, Cherati AS, et al. Relationship of aerobic fitness with cardiovascular risk factors in firefighters. Work 2016;55:155-61.

3. Durand G, Tsismenakis AJ, Jahnke SA, et al. Firefighters' physical activity: relation to fitness and cardiovascular disease risk. Med Sci Sports Exerc 2011;43:1752-9.

4. Gendron P, Lajoie C, Laurencelle L, Trudeau F. Cardiovascular disease risk factors in Québec male firefighters. J Occup Environ Med 2018;60:e300-6.

5. Wolkow A, Netto K, Langridge P, et al. Cardiovascular risk screening of volunteer firefighters. In: Proceedings of Bushfire CRC \& AFAC 2012 Conference Research Forum. 2012.

6. Martin ZT, Schlaff RA, Hemenway JK, et al. Cardiovascular 
disease risk factors and physical fitness in volunteer firefighters. Int J Exercise Sci 2019;12:764-76.

7. Smith DL, Barr DA, Kales SN. Extreme sacrifice: Sudden cardiac death in the US Fire Service. Extreme Physiol Med 2013;2:1-9.

8. Jitnarin N, Poston WS, Haddock CK, et al. Tobacco use pattern among a national firefighter cohort. Nicotine Tob Res 2015; 17:66-73.

9. Savall A, Charles R, Binazet J, et al. Volunteer and career French firefighters with high cardiovascular risk epidemiology and exercise tests. J Occup Environ Med 2018;60:E548-53.

10. Soteriades ES, Kales SN, Liarokapis D, et al. Lipid profile of firefighters over time: Opportunities for prevention. J Occup Environ Med 2002;44:840-6.

11. American College of Sports Medicine. ACSM Guidelines for Exercise Testing and Prescription, $10^{\text {th }}$ ed. Philadelphia: Lippincott Williams \& Wilkins; 2018. p. 44-89.

12. American College of Sports Medicine. ACSM Guidelines for Exercise Testing and Prescription, $9^{\text {th }}$ ed. Philadelphia: Lippincott Williams \& Wilkins; 2013. p. 27-31.

13. Byczek L, Walton SM, Conrad KM, et al. Cardiovascular risks in firefighters: Implications for occupational health nurse practice. AAOHN J 2004;52:66-77.

14. Wolkow A, Hons B, Netto K, et al. Coronary heart disease risk in volunteer firefighters in Victoria, Australia. Arch Environ Occup Health 2014;69:112-20.

15. Gendron P, Lajoie C, Laurencelle L, Trudeau F. Cardiovascular disease risk in female firefighters. Occup Med 2018;68:412-4.

16. Padela AI. American Muslim health disparities: The state of the Medline. J Health Dispar Res Pract Lit 2015;8:1-9.

17. Soteriades ES, Kales SN, Liarokapis D, Christiani DC. Prospective surveillance of hypertension in firefighters. J Clin Hypertens (Greenwich) 2003;5:315-20.

18. Eastlake AC, Knipper BS, He X, et al. Lifestyle and safety practices of firefighters and their relation to cardiovascular risk factors. Work 2015;50:285-94.

19. Damacena FC, Batista TJ, Ayres LR, et al. Obesity prevalence in Brazilian firefighters and the association of central obesity with personal, occupational and cardiovascular risk factors: a cross-sectional study. BMJ Open 2020;10:1-10.

20. Choi BK, Schnall P, Dobson M. Twenty-four-hour work shifts, increased job demands, and elevated blood pressure in professional firefighters. Int Arch Occup Environl Health 2016;89:1111-25.

21. Choi B, Dobson M, Schnall P, Garcia-Rivas J. 24-hour work shifts, sedentary work, and obesity in male firefighters. Am J Ind Med 2016;59:486-500.

22. Mehrdad R, Movasatian F, Momenzadeh AS. Fitness for work evaluation of firefighters in Tehran. Acta Medica Iranica 2013;51:265-9.

23. Santora LJ, Pillutla P, Norris T, et al. Coronary calcium scanning independently detects coronary artery disease in asymptomatic firefighters: A prospective study. J Cardiovasc Comput Tomogr 2013;7:46-50.

24. Glueck CJ, Kelley W, Gupta A, et al. Prospective 10-year evaluation of hypobetalipoproteinemia in a cohort of 772 firefighters and cross-sectional evaluation of hypocholesterolemia in
1,479 men in the National Health and Nutrition Examination Survey I. Metabolism 1997;46:625-33.

25. Smith DL, Graham E, Stewart D, Mathias KC. Cardiovascular disease risk factor changes over 5 years among male and female US firefighters. J Occup Environ Med 2020;62:398402.

26. Nor N, Lee CJ, Park KS, et al. The risk of mortality and cardiovascular disease is increased in firefighters with elevated blood pressure compared to the general population. J Hypertension 2019;37:e11.

27. Soteriades ES, Hauser R, Kawachi I, et al. Obesity and risk of job disability in male firefighters. Occup Med 2008;58:24550.

28. Reinberg AE, Smolensky MH, Riedel M, et al. Do night and around-the-clock firefighters' shift schedules induce deviation in tau from 24 hours of systolic and diastolic blood pressure circadian rhythms? Chronobiol Int 2017;34:1158-74.

29. Jang TW, Jeong KS, Ahn YS, Choi KS. The relationship between the pattern of shift work and sleep disturbances in Korean firefighters. Int Arch Occup Environ Health 2020;93:391-8.

30. Choi BK, Steiss D, Garcia-Rivas J, et al. Comparison of body mass index with waist circumference and skinfold-based percent body fat in firefighters: adiposity classification and associations with cardiovascular disease risk factors. Int Arch Occup Environ Health 2016;89:435-48.

31. Leary DB, Takazawa M, Kannan K, Khalil N. Perfluoroalkyl Substances and metabolic syndrome in firefighters: A pilot study. J Occup Environ Med 2020;62:52-7.

32. Clark S, Rene A, Theurer WM, Marshall M. Association of body mass index and health status in firefighters. J Occup Environ Med 2002;44:940-10.

33. Muegge CM, Zollinger TW, Song Y, et al. Barriers to weight management among overweight and obese firefighters. J Occup Environ Med 2020;62:37-45.

34. Jahnke SA, Poston WSC, Haddock CK, et al. The health of women in the US fire service. BMC Womens Health 2012;12:39.

35. Yoo HL, Franke WD. Prevalence of cardiovascular disease risk factors in volunteer firefighters. J Occup Environ Med 2009;5:958-62.

36. Lima E de P, Assunção AÁ, Barreto SM. [Smoking and occupational stressors in firefighters, 2011].[Article in Portuguese]. Rev Saude Publica 2013;47:897-904.

37. Cohen HW, Zeig-Owens R, Joe C, et al. Long-term cardiovascular disease risk among firefighters after the World Trade Center disaster. JAMA Network Open 2019;2:e199775.

38. Burgess JL, Kurzius-Spencer M, Gerkin RD, et al. Risk factors for subclinical atherosclerosis in firefighters. J Occup Environ Med 2012;54:328-35.

39. Jitnarin N, Poston WS, Haddock CK, et al. Tobacco use pattern among a national firefighter cohort. Nicotine Tob Res 2015;17:66-73.

40. Coker RH, Murphy CJ, Johannsen M, et al. Wildland firefighting: Adverse influence on indices of metabolic and cardiovascular health. J Occup Environ Med 2019;61:E91-4. 